\title{
Sonographer school, HRH Princess Chulabhorn College of Medical Science: The first step of the sonographer system in Thailand
}

Surachate Siripongsakun, M.D.

From Sonographer School, HRH Princess Chulabhorn College of Medical Science, Chulabhorn Royal Academy, Bangkok, Thailand.

Address correspondence to S.S. (e-mail: surachate@yahoo.com)

Keywords: Education, Sonographer school, Sonography, Ultrasonography, Ultrasound.

Ultrasound is a diagnostic imaging tool, which is convenient, inexpensive and it provides non-radiation exposure. Thus, it is commonly used in a real-time diagnostic method in almost all medical fields. Nowadays, medical technology is widely used along with much more advanced development and ultrasound is considered a medical disruptive technology that is expected to expand in a wider scale in the near future.

In Thailand, ultrasonography still requires specialized physicians, especially radiologists, and obstetricians, resulting in some limitations and non-real time with an increasing number of services and long waiting time of patients in government hospitals before examinations, which could delay diagnosis and treatments.

In various developed countries such as Europe, America, and Australia, the medical sonographer has been developed as a system for diagnostics and ultrasound imaging among specialized physicians to perform and do a preliminary report of the ultrasound imaging, resulting in much lower waiting and more efficiency in the diagnostic examination. 
In ASEAN countries, most of the ultrasound studies are provided by medical doctors; therefore, sonography training is still limited for physicians. Only a few countries including Singapore, Malaysia, and Thailand have formal training institutes for non-physician healthcare personnel at the level of post-graduate training, to provide formal sonography education/training to non-physician healthcare professions.

Basic information about the programs is provided in the table below (Table 1).

Table 1: Basic information of sonographer institutes in ASEAN region

\begin{tabular}{|c|c|c|c|}
\hline Country & Singapore & Malaysia & Thailand \\
\hline Institute & $\begin{array}{l}\text { Singapore Institute of } \\
\text { Technology, Singapore }\end{array}$ & $\begin{array}{l}\text { Vision College, } \\
\text { Selangor, Malaysia }\end{array}$ & $\begin{array}{c}\text { Sonographer School, } \\
\text { Princess Chulahborn College of } \\
\text { Medical Science } \\
\text { Bangkok, Thailand }\end{array}$ \\
\hline Programs offer & $\begin{array}{l}\text { Post graduate certificate } \\
\text { in sonography, } \\
\text { Post graduate diploma } \\
\text { in sonography }\end{array}$ & $\begin{array}{l}\text { Post graduate diploma } \\
\text { of medical ultrasonography }\end{array}$ & $\begin{array}{l}\text { Post graduate diploma } \\
\text { in medical sonography, } \\
\text { Master degree in medical } \\
\text { sonography }\end{array}$ \\
\hline Established since & No available online data & 2005 & 2018 \\
\hline Affiliation & No available online data & $\begin{array}{l}\text { University of South } \\
\text { Australia, Adelaide, } \\
\text { Australian Society of } \\
\text { Ultrasound in Medicine }\end{array}$ & $\begin{array}{c}\text { Monash University, Melbourne, } \\
\text { Australia }\end{array}$ \\
\hline $\begin{array}{l}\text { Clinical modules } \\
\text { provided }\end{array}$ & $\begin{array}{c}\text { Abdominal sonography } \\
\text { Pelvic Sonography } \\
\text { Obstetric Sonography } \\
\text { Small parts Sonography } \\
\text { Vascular Sonography } \\
\text { Musculoskeleton Sonography } \\
\text { Neonatal and Paediatric Sonography }\end{array}$ & $\begin{array}{l}\text { Abdominal sonography } \\
\text { Obstetric and Gynecology } \\
\text { Sonography } \\
\text { Small parts Sonography } \\
\text { Vascular Sonography } \\
\text { Musculoskeleton Sonography } \\
\text { Paediatric Sonography }\end{array}$ & $\begin{array}{c}\text { Abdominal sonography } \\
\text { Reproductive Sonography } \\
\text { Obstetric Sonography } \\
\text { Breast and thyroid Sonography } \\
\text { Vascular and post operative } \\
\text { Sonography } \\
\text { Musculoskeleton Sonography }\end{array}$ \\
\hline Souces & https://sitlearn.singaporetech.edu.sg/ & https://www.vision.edu.my/ & http://sonoschool.pccms.ac.th/ \\
\hline
\end{tabular}


"Chulabhorn Royal Academy" is a government educational institution founded and named by Professor Dr. HRH Princess Chulabhorn Krom Phra Srisavangavadhana. Due to the awareness of the importance of this personnel development, the establishment of a medical ultrasound school was thus approved. On 1 June 2016, the committee for the Sonographer School establishment, led by Professor Dr. Jiraporn Laothammatat as the school chairman, agreed to collaborate with Monash University, a well-known and recognized institution for the sonographer curriculum, following the coordination by Assoc. Prof. Dr. Napapong Pongnapang, the vice president of ISRT (Asia Pacific region), who knew some instructors and the Head of Radiation Technology Department very well.

Then, Chulabhorn Royal Academy and Monash University entered a signed MOU for the sonographer curriculum development and collaboration on June 30, 2017 (Figure 1). After that, on October 4-9, 2017, the Sonographer School and Monash University organized the program of "Train the Trainer" for the school's instructors so as to prepare them to teach sonographer courses. This program was officially the first to share and exchange knowledge and experiences in ultrasonography between the two institutions.

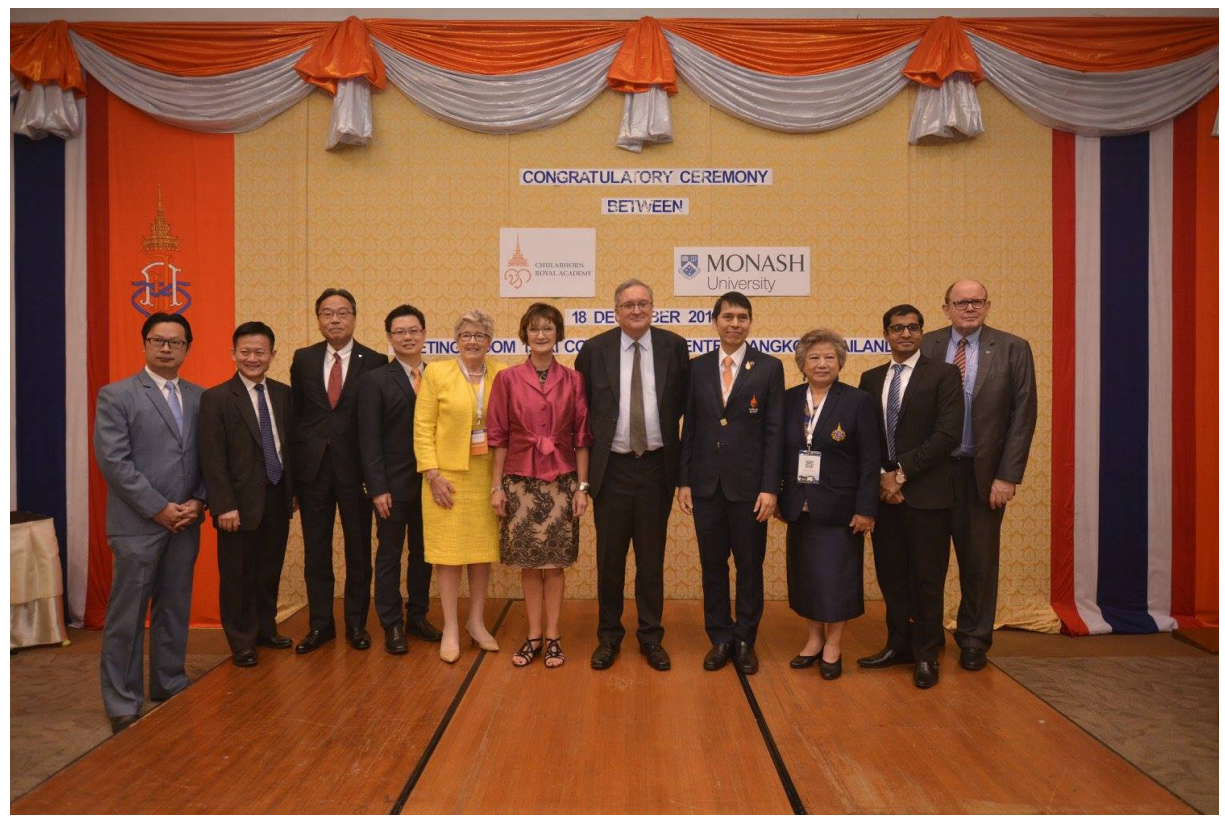

Figure 1: A signed MOU for the sonographer curriculum development and collaboration. 
On 1 December 2017, it was a very auspicious occasion that Professor Dr. HRH Princess Chulabhorn Krom Phra Srisavangavadhana proceeded to the ceremony for the official opening of the Sonographer School at Chulabhorn Chalermprakiet Medical Center Building, Lak Si District, Bangkok. It was the day of birth (Figure 2). The Sonographer School is the first sonographer school in Thailand, which initiated the admission of the 1st group of students in the Master of Science Program in Sonographer on August 1, 2018, onwards with Assistant Professor Dr. Surachate Siripongasakun as the first director of the school and the chairman of sonographer curriculum (Figure3).

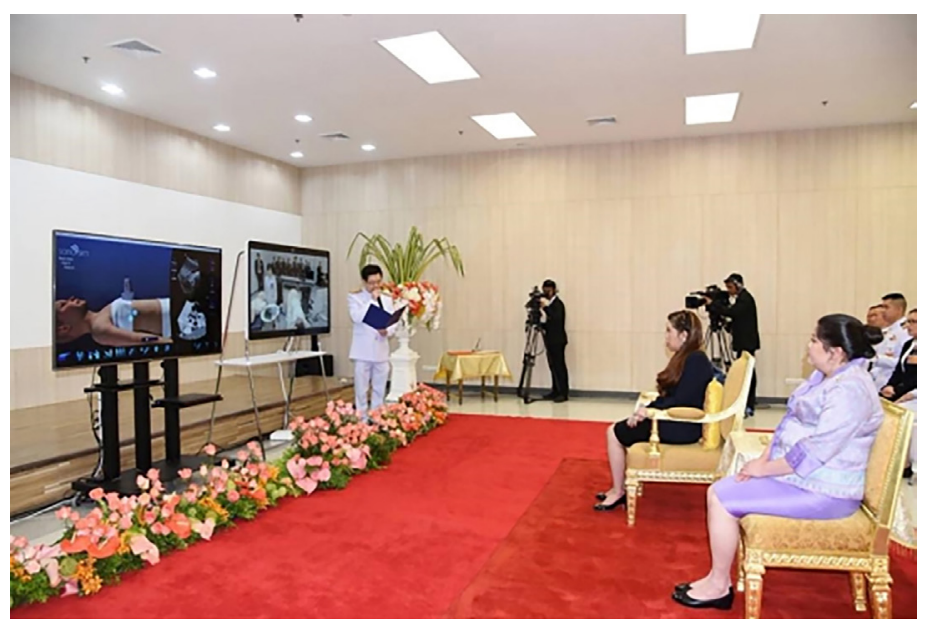

Figure 2: The official opening of the Sonographer School.

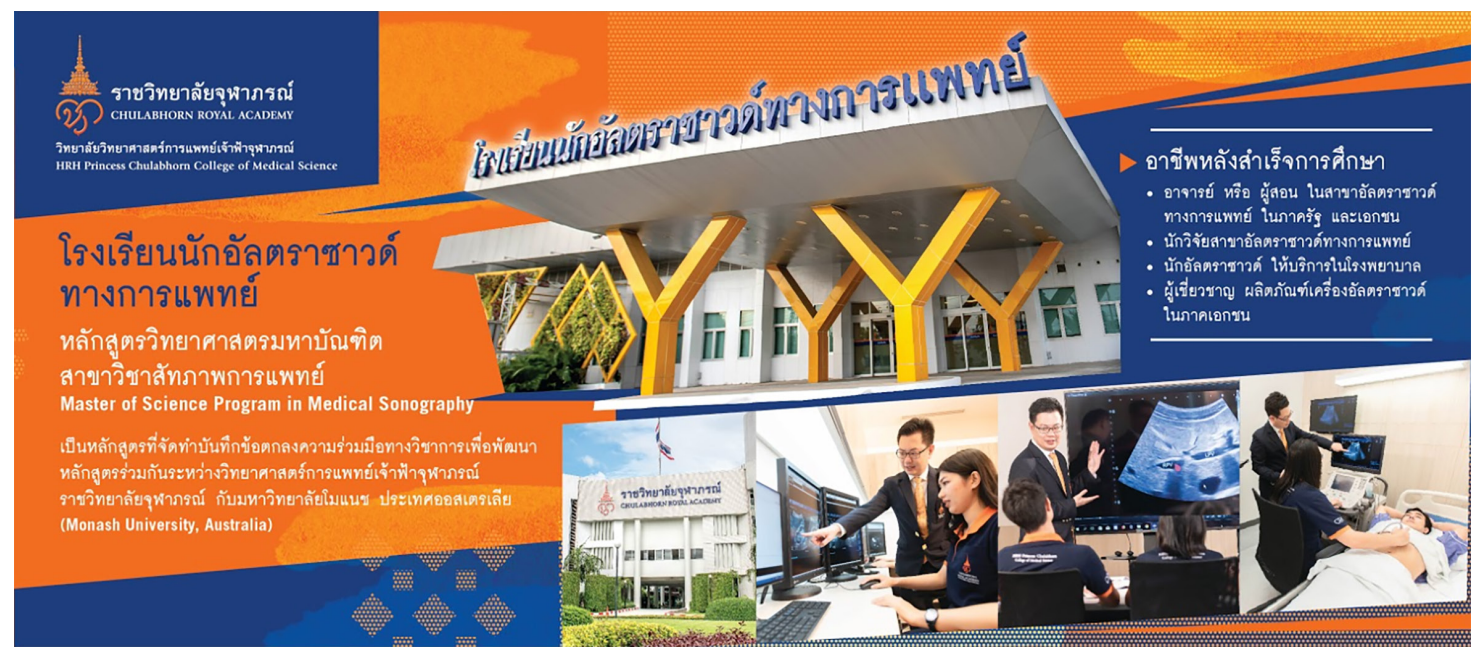

Figure 3: The first director of the school and the chairman of sonographer curriculum. 
The Sonographer School has opened many courses and programs for students as follows:

1. Master of Science Program in Medical Sonography

2. Postgraduate Diploma in Medical Sonography

The Sonographer School is an educational institution that supports the study of ultrasonography at all levels, ranging from specialized physicians, general practitioners, radiologists, nurses, and other related medical science personnel, aiming to develop these medical personnel to use ultrasound technology for diagnosis and treatments with the increasing capacity of sonographers in order to provide fast and thorough ultrasound services.

\section{Contact us}

The Sonographer School, Faculty of Health Science Technology

HRH Princess Chulabhorn College of Medical Science, Chulabhorn Royal Academy

906 Kampangpetch 6 Road, Talad Bangkhen, Laksi, Bangkok 10210, Thailand Tel. 66+02576-6000

Facebook: https://www.facebook.com/SonographerSchool/ 